\title{
Comparison of the Cardiomyogenic Potency of Human Amniotic Fluid and Bone Marrow Mesenchymal Stem Cells
}

\author{
Manali Jain ${ }^{1, *}$, Ekta Minocha ${ }^{1, *}$, Naresh Kumar Tripathy ${ }^{1}$, Neeta Singh $^{2}$, \\ Chandra Prakash Chaturvedi ${ }^{1}$, Soniya Nityanand ${ }^{1}$ \\ ${ }^{1}$ Stem Cell Research Centre, Department of Hematology, Sanjay Gandhi Post-Graduate Institute of Medical Sciences \\ (SGPGIMS), Lucknow, India \\ ${ }^{2}$ Department of Maternal Reproductive Health, Sanjay Gandhi Post-Graduate Institute of Medical Sciences \\ (SGPGIMS), Lucknow, India
}

\begin{abstract}
Background and Objectives: Most studies in cardiac regeneration have explored bone marrow mesenchymal stem cells (BM-MSC) with variable therapeutic effects. Amniotic fluid MSC (AF-MSC) having extended self-renewal and multipotent properties may be superior to bone marrow MSC (BM-MSC). However, a comparison of their cardiomyogenic potency has not been studied yet.

Methods: The 5-azacytidine (5-aza) treated AF-MSC and BM-MSC were evaluated for the expression of GATA-4, Nkx2.5 and ISL-1 transcripts and proteins by quantitative RT-PCR and Western blotting, respectively as well as for the expression of cardiomyogenic differentiation markers cardiac troponin-T (cTNT), beta myosin heavy chain $(\beta M H C)$ and alpha sarcomeric actinin (ASA) by immunocytochemistry.

Results: The AF-MSC as compared to BM-MSC had significantly higher expression of GATA-4 (183.06 \pm 29.85 vs. $9.80 \pm 0.05 ; \mathrm{p}<0.01), \mathrm{Nkx} 2.5(8.3 \pm 1.4$ vs. $1.82 \pm 0.32 ; \mathrm{p}<0.05)$, and ISL-1 $(39.59 \pm 4.05$ vs. $4.36 \pm 0.39 ; \mathrm{p}<0.01)$ genes as well as GATA-4 $(2.01 \pm 0.5$ vs. $0.6 \pm 0.1 ; \mathrm{p}<0.05)$, NKx2.5 $(1.9 \pm 0.14$ vs. $0.8 \pm 0.2 ; \mathrm{p}<0.01)$ and ISL-1 $(1.7 \pm 0.3$ vs. $0.9 \pm 0.1 ; \mathrm{p}<0.05)$ proteins. The AF-MSC also had significantly elevated expression of cTNT $\left(5.0 \times 10^{4} \pm 0.6 \times 10^{4}\right.$ vs. 3.5 $\left.\times 10^{4} \pm 0.8 \times 10^{4} ; \mathrm{p}<0.01\right), \beta-$ MHC $\left(15.7 \times 10^{4} \pm 0.9 \times 10^{4}\right.$ vs. $\left.8.2 \times 10^{4} \pm 0.6 \times 10^{4} ; \mathrm{p}<0.01\right)$ and ASA $\left(18.6 \times 10^{4} \pm 4.9 \times 10^{4}\right.$ vs. $\left.13.1 \times 10^{4} \pm 3.0 \times 10^{4} ; \mathrm{p}<0.05\right)$ than BM-MSC.

Conclusions: Our data suggest that AF-MSC have greater cardiomyogenic potency than BM-MSC, and thus may be a better source of MSC for therapeutic applications in cardiac regenerative medicine.
\end{abstract}

Keywords: Amniotic fluid mesenchymal stem cells, Bone marrow mesenchymal stem cells, Cardiomyogenic potency, Cardiac transcription factors, Cardiac structural markers

Received: September 25, 2018, Revised: February 25, 2019, Accepted: March 19, 2019, Published online: October 31, 2019 Correspondence to Soniya Nityanand

Department of Hematology, Sanjay Gandhi Post Graduate Institute of Medical Sciences, Raebareli Road, Lucknow 226014, India

Tel: +91-522-2494291, 2495959, Fax: +91-522-2668017, 2668078 E-mail: soniya_nityanand@yahoo.co.in / soniya@sgpgi.ac.in

${ }^{*}$ These authors contributed equally to this work.

(c) This is an open-access article distributed under the terms of the Creative Commons Attribution Non-Commercial License (http://creativecommons.org/ licenses/by-nc/4.0/), which permits unrestricted non-commercial use, distribution, and reproduction in any medium, provided the original work is properly cited.

Copyright (c) 2019 by the Korean Society for Stem Cell Research

\section{Introduction}

Mesenchymal stem cells (MSC) have been extensively explored for cardiac regeneration because of their potential to differentiate into cardiomyocytes in vitro and in vivo $(1,2)$. They can be derived from almost all adult tissues of the body, the common sources being bone marrow, adipose tissue and dental tissues. MSC can also be obtained from fetal tissues such as amniotic fluid, umbilical cord blood and Wharton's jelly (3). Of these, the bone marrow (BM) derived MSC (BM-MSC) have been most commonly 
studied for myocardial regeneration in several pre-clinical and clinical studies but the therapeutic outcome has been variable, which may be because of their limited cardiomyogenic potential (4-6). The collection of MSC from $\mathrm{BM}$ entails an invasive procedure and it is difficult to get MSC from healthy individuals. Moreover, the frequency of MSC in the BM is very low (0.001 to $0.01 \%)$ and their numbers and functionality decreases with the donor's age $(7,8)$.

Amniotic fluid (AF) is a novel source of stem cells derived from all the three germ layers (9). The AF derived MSC (AF-MSC) are primitive mesodermal progenitors with extended self-renewal properties and multi-lineage differentiation potential. $\mathrm{AF}$ is obtained via amniocentesis for pre-natal diagnosis of genetic disorders and contains a higher frequency of MSC (0.9 to $1.5 \%)$ than in the BM. In addition to prototype mesenchymal markers, AF-MSC express several pluripotency related markers and transcription factors including Oct-4, Sox2, c-Kit, TRA-1-60 and TRA-1-80 highlighting that they are intermediate between embryonic and adult stem cells $(10,11)$. A comparison of molecular and proteomic characterization of AF-MSC and BM-MSC has revealed that AF-MSC express a number of unique proteins related to self renewal and primitive stemness making them distinct from BM-MSC (12). They have also been demonstrated to have a greater hepatogenic and neural differentiation potential than BM-MSC $(13,14)$. In addition, AF-MSC are immunologically privileged stem cells with higher immunomodulatory characteristics than BM-MSC and they can be used for translational purpose under allogenic conditions $(15,16)$. Thus overall AF-MSC may be a more suitable source than BM-MSC for regenerative therapies. There are sporadic studies showing differentiation of AF-MSC into cardiac lineage (17) but a comparative analysis of cardiomyogenic potency of AF- and BM-MSC has not yet been carried out.

Therefore, the goal of this study was to compare the expression of cardiac transcription factors and cardiomyogenic differentiation markers between AF-MSC and BM-MSC, in order to ascertain whether AF-MSC have a superior cardiac potency than BM-MSC.

\section{Materials and Methods}

\section{Isolation and culture of human AF-MSC and BM-MSC}

Approximately $5 \mathrm{ml}$ of AF from healthy pregnant females $(n=10)$ of gestation week $12 \sim 18$ were collected during routine amniocentesis after informed consent. The $\mathrm{AF}$ cells obtained after centrifugation were resuspended in MSC growth medium (MSCGM) consisting of $\alpha$-MEM supplemented with $16.5 \%$ fetal bovine serum, $1 \%$ gluta$\max$ and $1 \%$ bacteriostatic levels of penicillin-streptomycin (Gibco, MD, USA). The cells were seeded in T-25 $\mathrm{cm} 2$ flasks (BD Falcon) and incubated at $37^{\circ} \mathrm{C}$ under $5 \%$ $\mathrm{CO}_{2}$. The medium containing non-adherent cells was changed on every 3 rd day. The primary cultures of AFMSC with semi-confluent growth were passaged by trypsinization and further expanded under the same culture conditions. The BM samples of patients with nutritional anemia or immune thrombocytopenia (ITP) $(n=10)$ undergoing routine marrow examination were collected after informed consent and the BM-MSC were isolated and cultured using a protocol previously published by our laboratory (18). The cells of the $3^{\text {rd }}$ passage were used in the experiments.

\section{Growth kinetics}

The $3^{\text {rd }}$ passage MSC were seeded in triplicate at the concentration of $1 \times 10^{4}$ cells per well in a six well plate. The cells were harvested and counted at 24, 48, 72, 96 and 120 hours. The growth curves were plotted using GraphPad Prism. The population doubling time was calculated according to the following formula.

$$
\text { Population Doubling Time }=\frac{\log 2}{\operatorname{logNt}-\log \mathrm{No}_{\mathrm{O}}} \times \mathrm{t}
$$

Where: $\mathrm{Nt}=$ ultimate cell number; $\mathrm{No}=$ primary cell number; $\mathrm{t}=$ termination incubation time.

\section{Flow cytometry}

The cells were stained with following pre-conjugated monoclonal antibodies: CD73-Phycoerythrin (PE), CD90-PE, CD105-PE, CD34-fluorescein isothiocyanate (FITC) CD45FITC, HLA-DR-FITC. After 30 minutes of incubation at room temperature, the cells were acquired in FACS-calibur flow cytometer (BD Biosciences) and the data was analysed using FCS Express software.

\section{Adipogenic, osteogenic and chondrogenic differentiation}

Adipogenic, osteogenic and chondrogenic differentiation of AF-MSC and BM-MSC were determined by OilRed O, Alizarin Red and Alcian blue staining respectively, using the StemPro kits (Gibco) according to manufacturer's instruction as described previously (18).

\section{Cardiomyogenic induction of AF-MSC and BM-MSC}

Cells were induced into cardiomyogenic lineage by treating with MSCGM containing $10 \mu \mathrm{M}$ 5-Azacytidine (5- 
aza; Sigma-Aldrich MO, USA) (20). After 24 hrs, cells were washed and further incubated in MSCGM alone up to four weeks with the change of medium twice a week. These cells were analyzed for expression of cardiac transcription factors using real-time qPCR and western blot respectively and the expression of cardiac structural markers were determined by immunocytochemistry.

\section{Real-time qPCR}

Total RNA was isolated from control and 5-aza treated

Table 1. List of primer sequences used for RT-qPCR

\begin{tabular}{clc}
\hline Gene & \multicolumn{1}{c}{ Primer sequence } & Accession No. \\
\hline GATA-4 & $\begin{array}{l}\text { Forward: 5' TCCAAACCAGAAAACGGAAG 3' } \\
\text { Reverse: 5' CTGTGCCCGTAGTGAGATGA3' }\end{array}$ & NM_002052.3 \\
Nkx2.5 & $\begin{array}{l}\text { Forward: 5' AGTTTGTGGCGGCGATTAT 3' } \\
\text { Reverse: 5' AGCTCAGTCCCAGTTCCA 3 }\end{array}$ & NM_004387.3 \\
ISL-1 & $\begin{array}{l}\text { Forward: 5' GCCTTGCAGAGTGACATAGAT 3' } \\
\text { Reverse: 5'CTGGAAGTTGAGAGGACATTGA3' }\end{array}$ & NM_002202.2 \\
GAPDH & Forward: 5'AATCCCATCACCATCTTCCA 3' & NM_002046.4 \\
& Reverse: 5' TGGACTCCACGACGTACTCA 3 & \\
\hline
\end{tabular}

a)

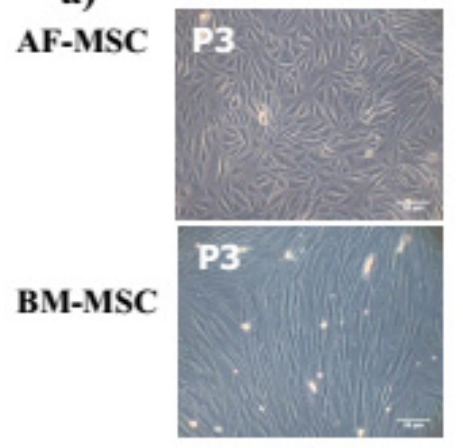

d)
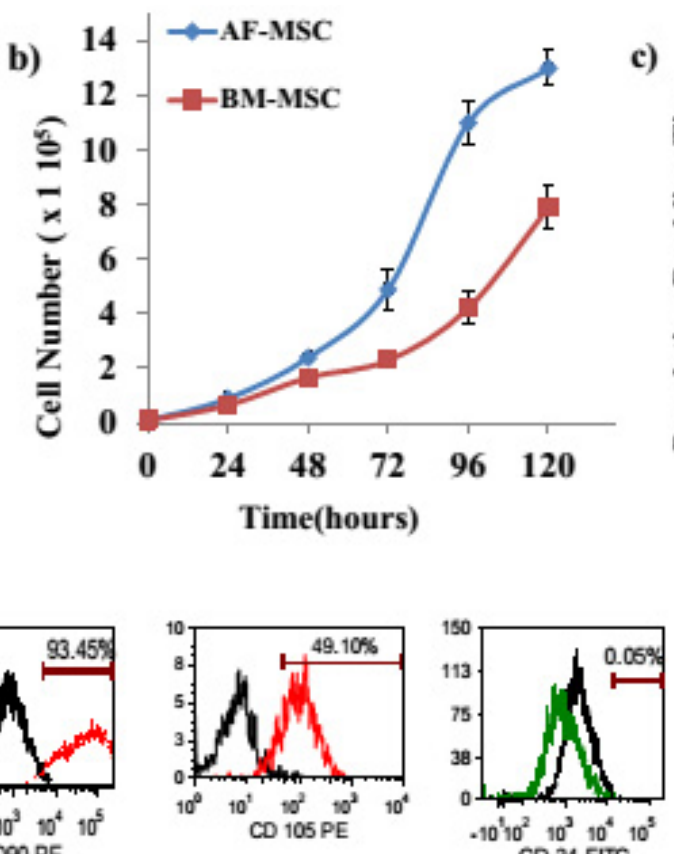

CD 34 FITC

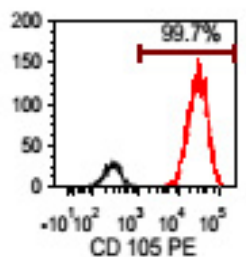

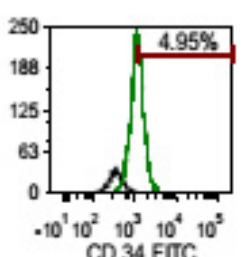

$\operatorname{CD} 34 \mathrm{FITC}$
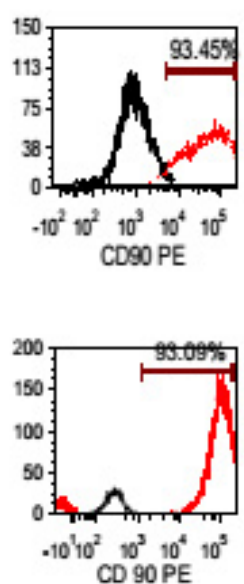
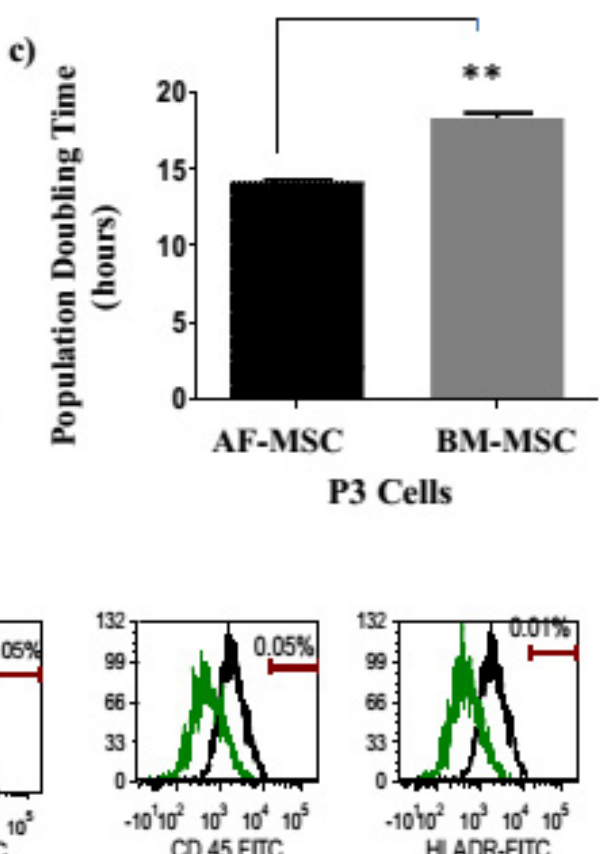

CD 45 FIC
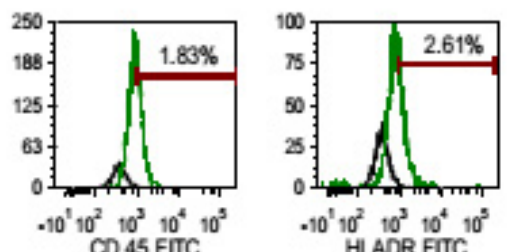

Fig. 1. Morphological and characterization of AF-MSC and BM-MSC. (a) Representative photomicrographs (10X, 10 micron) of AF-MSC and BM-MSC showing a trigonal and fibroblastoid morphology respectively in 3rd passage; (b, c) Proliferation rate and Population Doubling Time (PDT) of the both AF-MSC and BM-MSC at different hours; (d) Representative flow cytometric histogram of AF-MSC and BM-MSC showing the presence of MSC markers (CD73, CD90 and CD105) \& absence of hematopoietic stem cell markers (CD34, CD45 and HLA-DR). Values expressed as Mean $\pm \mathrm{SD} ; * * \mathrm{p}<0.01$. 
cells using the Trizol Reagent (Invitrogen, Waltham Massachusetts, USA). The mRNA was reverse transcribed to cDNA using high capacity cDNA reverse transcription kit (Applied Biosystem). Real-Time analysis of GATA-4, NKx2.5 ISL-1 and GAPDH expression was performed using SYBR Green PCR MASTER mix assay (Takara Clontech). The relative expression level for each target gene was normalized by the $\mathrm{Ct}$ value of the housekeeping gene and determined by using the ${ }^{\Delta \Delta} \mathrm{Ct}$ method. The fold change in gene expression was calculated using $2^{-\Delta \Delta \mathrm{CT}}$ method as reported previously (18). Primers used for quantitative real-time PCR are shown in Table 1.

\section{Western blotting}

Approximately $20 \mu \mathrm{g}$ of nuclear extract prepared from 5 -aza treated and untreated cells was loaded and separated by $12 \%$ sodium dodecyl sulfate-polyacrylamide gel electro- phoresis. The separated proteins were transferred to nitrocellulose membranes and blocked with 5\% nonfat milk for 1 hour at room temperature. The membrane then incubated at $4^{\circ} \mathrm{C}$ overnight against primary antibodies viz. GATA-4 ( $1: 500$ dilution), NKx2.5 ( $1: 500$ dilution), and ISL-1 ( $1: 300$ dilution). Primary antibodies were detected by corresponding horseradish peroxidase (HRP)-conjugated secondary antibodies using super signal west picochemiluminescent substrate (Bio-Rad, USA). Images were developed using chemi-doc system (Biorad). The bands were quantified by densitometry using the Image-J software.

\section{Immunocytochemistry}

The 5-aza treated cells were fixed with $4 \%$ paraformaldehyde (Sigma) for $1 \mathrm{hr}$ at room temperature. After washing, cells were permeabilized with $0.5 \%$ triton $\mathrm{X}$ - for 10 minutes and non-specific protein binding was blocked by a)

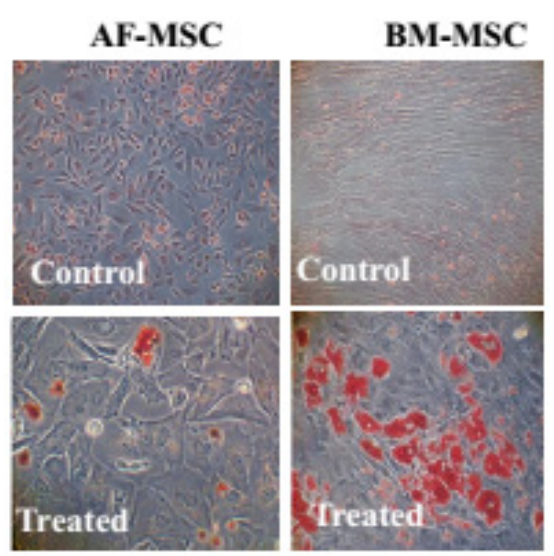

Adipogenic differentiation

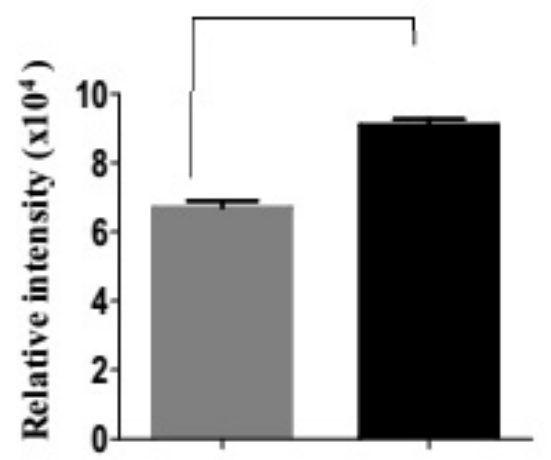

b)

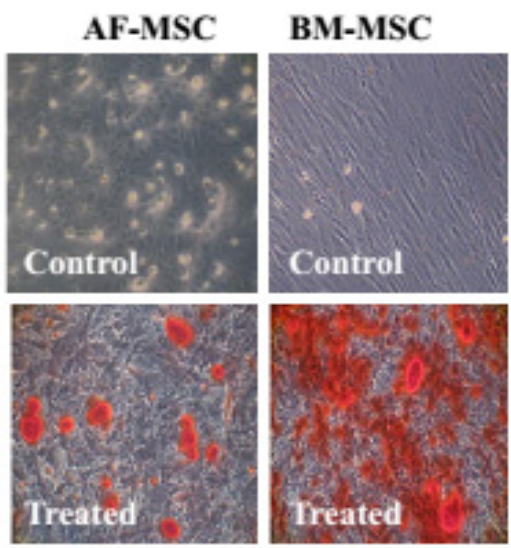

Osteogenic differentiation

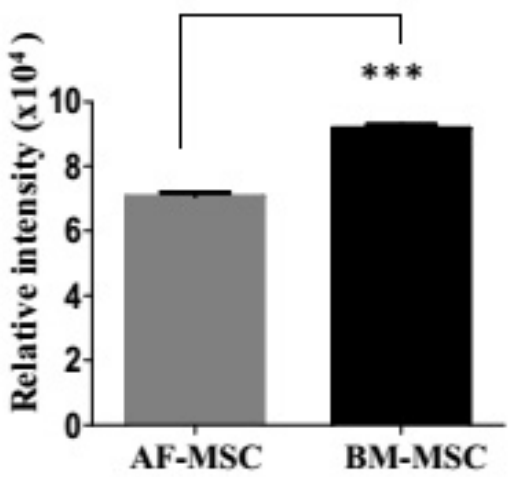

c)

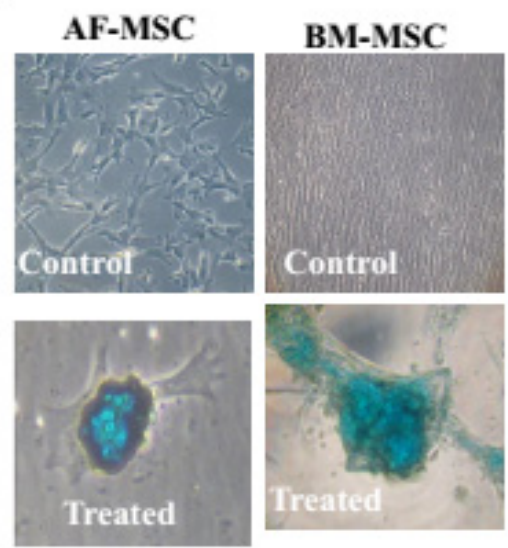

Chondrogenic differentiation

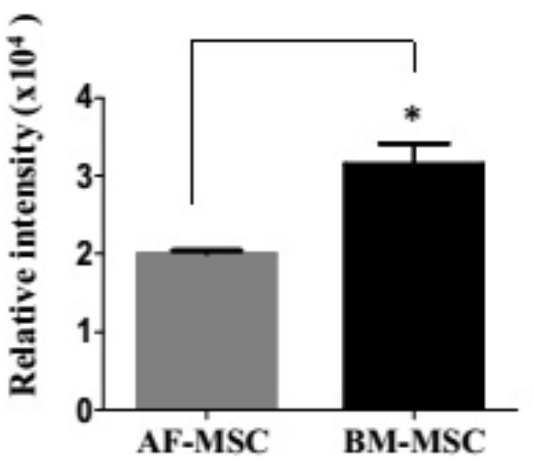

Fig. 2. Adipogenic, osteogenic and chondrogenic differentiation of AF-MSC and BM-MSC. Representative photomicrographs showing the differentiation of AF-MSC and BM-MSC into (a) adipocytes, as demonstrated with Oil red O Staining and their relative intensity, (b) osteocytes, as demonstrated with Alizarin red staining and their relative intensity, (c) chondrocytes, as demonstrated with Alcian blue staining and their relative intensity. Control AF-MSC and BM-MSC (untreated cells) were negative for Oil red O, Alizarin red and Alcian Blue staining, respectively. Values expressed as Mean $\pm \mathrm{SD} ;{ }^{* *} \mathrm{p}<0.01,{ }^{* * *} \mathrm{p}<0.001,{ }^{*} \mathrm{p}<0.05$ respectively. 
incubating the cells with 5\% normal sheep serum. The fixed cells were incubated overnight at $4{ }^{\circ} \mathrm{C}$ with $1: 200$ diluted cTNT (cardiac Toponin T), ASA (Alpha Sarcomeric Actinin), $\beta$ MHC (Beta myosin heavy chain) (abcam) antibodies. After wash, the cells were incubated with $1: 200$ diluted FITC labeled anti-mouse and anti-rabbit secondary antibody (abcam). The cells were then stained with $500 \mu 1$ of Hoechst and images were taken using Fluorescent microscope (Olympus BX61). The fluorescence intensity was quantified by Image-J software.

\section{Statistical analysis}

The statistical analysis was done using the paired t test and $p$ value of $<0.05$ was considered to be statistically significant. Data expressed as median or mean \pm standard deviation.

\section{Results}

\section{Characterization of AF-MSC and BM-MSC}

The AF-MSC exhibited spindle shaped morphology while BM-MSC exhibited elliptical fibroblastoid morphology (Fig. 1a). The BM-MSC had a significantly higher population doubling time (PDT) in comparison to AFMSC $(18.32 \pm 0.5$ vs.14.17 $\pm 0.24 ; \mathrm{p}<0.01)$. Both MSC types had a comparable expression of mesenchymal markers CD73, CD90 and were negative for CD34, CD45 and HLA-DR. However, AF-MSC had markedly lower expression of $\mathrm{CD} 105(49.1 \% \pm 23.8$ vs $99.7 \% \pm 3.2)$ as compared to BM-MSC (Fig. 1d). The AF-MSC exhibited low adipogenic, osteogenic and chondrogenic differentiation in comparison to a robust differentiation BM-MSC into these lineages (Fig. 2).
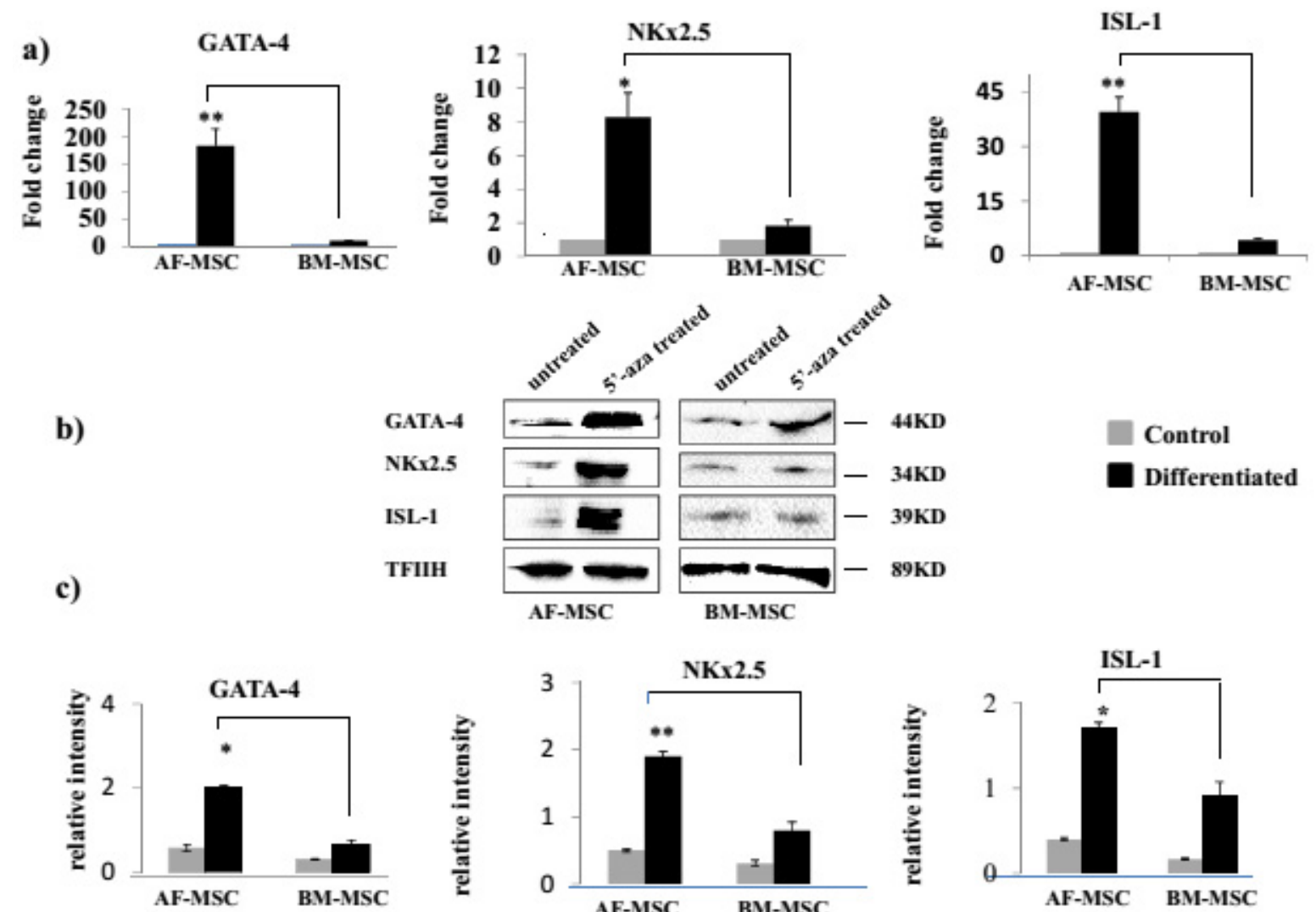

Control

Differentiated

Fig. 3. Expression of genes and proteins of cardiac transcription factors in AF- MSC and BM-MSC. (a) Representative reverse-transcription polymerase chain reaction photomicrographs showing expression of Cardiac transcription factors in 5-azacytitdine treated and untreated (control) AF-MSC and BM-MSC for GATA-4, NKx2.5 and ISL-1. Values expressed as Mean \pm SD; $* * \mathrm{p}<0.01, * \mathrm{p}<0.05, * * \mathrm{p}<0.01$ respectively. (b) Representative immune-blots showing expression of the GATA-4, NKx2.5 and ISL-1 in both control and 5-aza treated in AF-MSC and BM-MSC (c) their relative intensity applied for comparison of relative protein expression. Values expressed as Mean \pm SD; $* \mathrm{p}<0.05, * * \mathrm{p}<0.01,{ }^{*} \mathrm{p}<0.05$ between differentiated vs. control respectively. 


\section{Expression of cardiac transcription factors by AF-MSC and BM-MSC}

There was no difference between AF-MSC and BM-MSC in the constitutive expression of GATA-4 (1.1 \pm 0.23 vs $1.02 \pm 0.15, \mathrm{p}>0.05), \mathrm{Nkx} 2.5(1.01 \pm 0.22$ vs $1.17 \pm 0.11, \mathrm{p}>$ $0.05)$ and Isl1 $(0.9 \pm 0.03$ vs $1.01 \pm 0.12, \mathrm{p}>0.05)$ transcripts. However, after 5-Aza treatment, AF-MSC as compared to BM-MSC had significantly higher expression of GATA-4 (183.06 \pm 29.85 vs. $9.80 \pm 0.05 ; \mathrm{p}<0.01), \mathrm{Nkx} 2.5$ $(8.3 \pm 1.4$ vs. $1.82 \pm 0.32 ; \mathrm{p}<0.05)$, and ISL-1 $(39.59 \pm 4.05$ vs. $4.36 \pm 0.39 ; \mathrm{p}<0.01$ ) transcripts (Fig. 3a).

We further confirmed expression of these cardiac transcription factors at protein level in 5-Aza treated MSC using western blot and observed that similar to transcripts, the expression of GATA-4 $(2.01 \pm 0.5$ vs $0.6 \pm 0.1 ; \mathrm{p}<0.05)$, NKx2.5 (1.9 \pm 0.14 vs $0.8 \pm 0.2 ; p<0.01)$ and ISL-1 $(1.7 \pm 0.3$ vs $0.9 \pm 0.1 ; \mathrm{p}<0.05)$ proteins were significantly higher in AF-MSC as compared to BM-MSC (Fig. $3 \mathrm{~b}$ and 3c).

\section{Expression of cardiomyogenic markers by AF-MSC and BM-MSC;}

The expression of cardiomyogenic differentiation markers cTNT, $\beta$ MHC and ASA by 5-aza treated cells was analyzed by fluorescent immunocytochemistry. Quantitative analysis of immunoflorescent images revealed that as compared to BM-MSC, AF-MSC had significantly higher expression of cTNT $\left(5.0 \times 10^{4} \pm 0.6 \times 10^{4}\right.$ vs $3.5 \times 10^{4} \pm 0.8 \times 10^{4}$; $\mathrm{p}<0.01), \quad \beta$ MHC $\left(15.7 \times 10^{4} \pm 0.9 \times 10^{4}\right.$ vs $8.2 \times 10^{4} \pm 0.6 \times$ $\left.10^{4} ; \mathrm{p}<0.01\right)$ and ASA $\left(18.6 \times 10^{4} \pm 4.9 \times 10^{4}\right.$ vs $13.1 \times 10^{4} \pm$ $3.0 \times 10^{4} ; \mathrm{p}<0.05$ ) (Fig. 4).

\section{Discussion}

Our study shows that AF-MSC are the population of stem cells distinct from BM-MSC, and following cardiomyogenic induction with 5-aza they exhibited a higher expression of GATA-4, Nkx-2.5 and ISL-1 transcripts and a)

CTNT

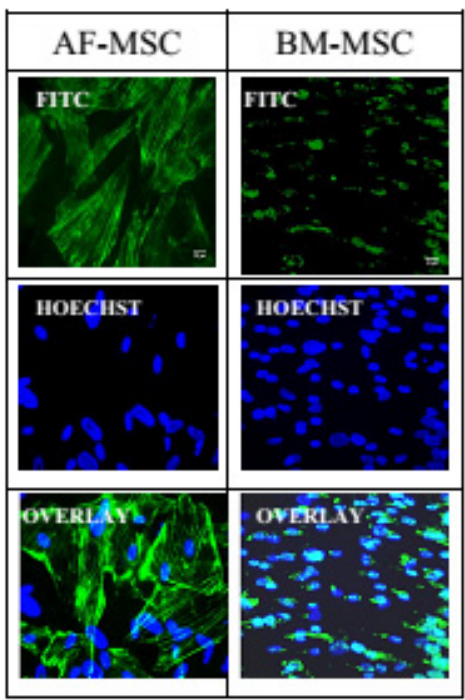

b)

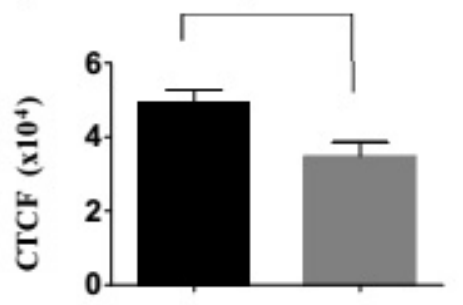

BMHC
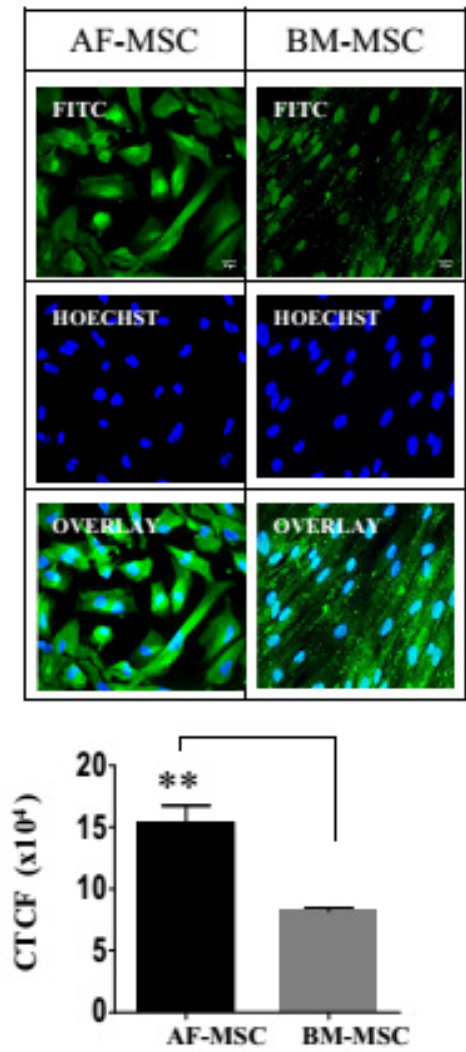

ASA
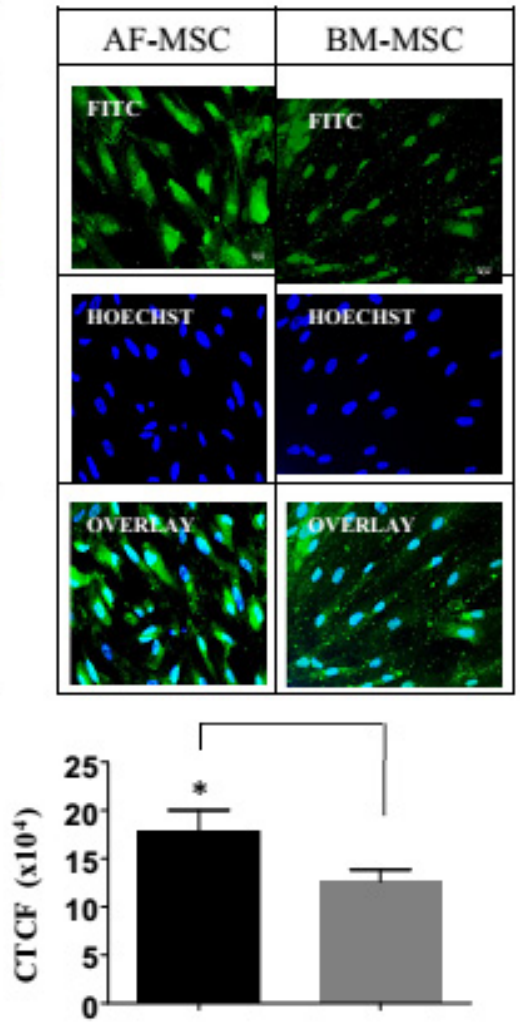

Fig. 4. Expression of cardiac structural markers in AF- MSC and BM-MSC. (a) Representative immunofluorescence photomicrographs (40x, 10 micron) of 5 aza treated AF-MSC and BM-MSC staining of cTNT, $\beta$ MHC, and ASA proteins; (b) their relative intensity was applied for comparison of relative protein expression. Values expressed as Mean $\pm \mathrm{SD} ; * * \mathrm{p}<0.01 ; * * \mathrm{p}<0.01,{ }^{*} \mathrm{p}<0.05$ between differentiated vs. control respectively.

CTCF (Corrected Total Cell Fluorescence)=Integrated Density -(Area of selected cell $\times$ Mean fluorescence of background readings). 
proteins as well as cardiomyogenic structural markers cTNT, $\beta$ MHC and ASA as compared to BM-MSC. To the best of our knowledge, this is the first study on a comparative analysis of cardiomyogenic potency of AF-MSC and BM-MSC.

The AF-MSC had a higher proliferative potential than BM-MSC, as reported previously (12). Both MSC types showed comparable expression of mesenchymal markers CD73 and CD90 and were negative for hematopoietic markers and HLA-DR. However, the expression of CD105 (the transforming growth factor-beta receptor endoglin) was seen in $99.7 \%$ of BM-MSC, whereas only in $49.1 \%$ of AF-MSC. It has been previously reported too, that AFMSC express low levels of CD105 (11). Using standard induction methods, AF-MSC exhibited lower adipogenic and osteogenic differentiation in comparison to BM-MSC. Although, not reported for AF-MSC, but similar to our observation fetal MSC derived from Wharton's jelly, have recently been shown to have a lower potential to differentiate into adipogenic and osteogenic lineages as compared to BM-MSC (19). Thus there was a difference in the phenotypic marker profile and in the adipogenic and osteogenic and chondrogenic differentiation potential of AF-MSC and BM-MSC.

Though under undifferentiated conditions both MSC types had a comparable expression of cardiac transcription factors GATA-4, Nkx2.5 and ISL-1 genes but after 5-Aza induction, AF-MSC exhibited a significantly higher expression of these transcription factors at gene as well as protein levels. These transcription factors are key regulators of the expression of cardiac structural genes in MSC as well as in other stem cells and promote their differentiation into cardiomyocytes (20, 21). Among these, ISL-1 is of particular importance as it is the earliest transcription factor having a crucial role in cardiogenesis during embryonic development and cardiomyocyte differentiation following cardiac injury in adults (22) and we have observed $40 \%$ of AF-MSC to express ISL-1. Similar to the expression of cardiac transcription factors, we observed that 5-aza induced AF-MSC had a significantly higher expression of cTNT, $\beta$ MHC and ASA as compared to BM-MSC. Thus our data collectively suggests that AFMSC have superior cardiomyogenic potency as compared to BM-MSC. Although, there is no previous report comparing the cardiomyogenic potential of human AF-MSC and BM-MSC, but several studies have also reported a limited cardiomyogenic potential of BM-MSC (6). We have previously shown that BM-MSC exhibit clonal heterogeneity and only 1 out of 4 clones possessed cardiomyogenic potential, highlighting a low frequency of car- diomyogenic cells in BM-MSC (17). It has also been previously shown that AF-MSC have superior neural and hepatic potency in comparison to BM-MSC $(13,14)$.

In conclusion, our data on cardiac transcription factors and cardiomyogenic differentiation markers in 5-aza treated cells together highlights that AF-MSC have greater cardiomyogenic potency than BM-MSC. Further studies on the cardiomyogenic secretory factors of AF-MSC, functional characteristics of the AF-MSC derived cardiomyocytes and therapeutic efficacy of AF-MSC in experimental models of cardiovascular diseases are required for establishing the role of AF-MSC in cardiac regeneration.

\section{Acknowledgments}

This work was supported by an Extramural Grant (BT/ PR16863/MED/31/338/2016) of Dept of Biotechnology (DBT), Govt. of India sanctioned to SN and Wellcome Trust DBT India Alliance Fellowship (IA/I/16/1/502374) sanctioned to CPC.

\section{Potential Conflict of Interest}

The authors have no conflicting financial interest.

\section{References}

1. Duran JM, Makarewich CA, Sharp TE, Starosta T, Zhu F, Hoffman NE, Chiba Y, Madesh M, Berretta RM, Kubo H, Houser SR. Bone-derived stem cells repair the heart after myocardial infarction through transdifferentiation and paracrine signaling mechanisms. Circ Res 2013;113:539-552

2. Karantalis V, Hare JM. Use of mesenchymal stem cells for therapy of cardiac disease. Circ Res 2015;116:1413-1430

3. Elahi KC, Klein G, Avci-Adali M, Sievert KD, MacNeil S, Aicher WK. Human mesenchymal stromal cells from different sources diverge in their expression of cell surface proteins and display distinct differentiation patterns. Stem Cells Int 2016;2016:5646384

4. Pandey AC, Lancaster JJ, Harris DT, Goldman S, Juneman E. Cellular therapeutics for heart failure: focus on mesenchymal stem cells. Stem Cells Int 2017;2017:9640108

5. Afzal MR, Samanta A, Shah ZI, Jeevanantham V, AbdelLatif A, Zuba-Surma EK, Dawn B. Adult bone marrow cell therapy for ischemic heart disease: evidence and insights from randomized controlled trials. Circ Res 2015;117:558575

6. Martin-Rendon E, Sweeney D, Lu F, Girdlestone J, Navarrete C, Watt SM. 5-Azacytidine-treated human mesenchymal stem/progenitor cells derived from umbilical cord, cord blood and bone marrow do not generate cardiomyocytes in vitro at high frequencies. Vox Sang 2008;95: 137-148

7. Stolzing A, Jones E, McGonagle D, Scutt A. Age-related changes in human bone marrow-derived mesenchymal stem 
cells: consequences for cell therapies. Mech Ageing Dev 2008;129:163-173

8. Fan M, Chen W, Liu W, Du GQ Jiang SL, Tian WC, Sun $\mathrm{L}$, Li RK, Tian H. The effect of age on the efficacy of human mesenchymal stem cell transplantation after a myocardial infarction. Rejuvenation Res 2010;13:429-438

9. Loukogeorgakis SP, De Coppi P. Concise review: amniotic fluid stem cells: the known, the unknown, and potential regenerative medicine applications. Stem Cells 2017;35:16631673

10. Antonucci I, Stuppia L, Kaneko Y, Yu S, Tajiri N, Bae EC, Chheda SH, Weinbren NL, Borlongan CV. Amniotic fluid as a rich source of mesenchymal stromal cells for transplantation therapy. Cell Transplant 2011;20:789-795

11. Savickiene J, Treigyte G, Baronaite S, Valiuliene G, Kaupinis A, Valius M, Arlauskiene A, Navakauskiene R. Human amniotic fluid mesenchymal stem cells from second- and third-trimester amniocentesis: differentiation potential, molecular signature, and proteome analysis. Stem Cells Int 2015;2015:319238

12. Roubelakis MG, Pappa KI, Bitsika V, Zagoura D, Vlahou A, Papadaki HA, Antsaklis A, Anagnou NP. Molecular and proteomic characterization of human mesenchymal stem cells derived from amniotic fluid: comparison to bone marrow mesenchymal stem cells. Stem Cells Dev 2007;16:931952

13. Zheng YB, Gao ZL, Xie C, Zhu HP, Peng L, Chen JH, Chong YT. Characterization and hepatogenic differentiation of mesenchymal stem cells from human amniotic fluid and human bone marrow: a comparative study. Cell Biol Int 2008;32:1439-1448

14. Yan ZJ, Hu YQ, Zhang HT, Zhang P, Xiao ZY, Sun XL, Cai YQ, Hu CC, Xu RX. Comparison of the neural differentiation potential of human mesenchymal stem cells from amniotic fluid and adult bone marrow. Cell Mol Neurobiol 2013;33:465-475

15. Mareschi K, Castiglia S, Sanavio F, Rustichelli D, Muraro M, Defedele D, Bergallo M, Fagioli F. Immunoregulatory effects on T lymphocytes by human mesenchymal stromal cells isolated from bone marrow, amniotic fluid, and placenta. Exp Hematol 2016;44:138-150.el

16. Ramasamy TS, Velaithan V, Yeow Y, Sarkar FH. Stem cells derived from amniotic fluid: a potential pluripotent-like cell source for cellular therapy? Curr Stem Cell Res Ther 2018;13:252-264

17. Markmee R, Aungsuchawan S, Narakornsak S, Tancharoen W, Bumrungkit K, Pangchaidee N, Pothacharoen $\mathrm{P}$, Puaninta C. Differentiation of mesenchymal stem cells from human amniotic fluid to cardiomyocyte-like cells. Mol Med Rep 2017;16:6068-6076

18. Tripathy NK, Rizvi SHM, Singh SP, Garikpati VNS, Nityanand S. Cardiomyogenic heterogeneity of clonal subpopulations of human bone marrow mesenchymal stem cells. J Stem Cells Regen Med 2018;14:27-33

19. Batsali AK, Pontikoglou C, Koutroulakis D, Pavlaki KI, Damianaki A, Mavroudi I, Alpantaki K, Kouvidi E, Kontakis G, Papadaki HA. Differential expression of cell cycle and WNT pathway-related genes accounts for differences in the growth and differentiation potential of Wharton's jelly and bone marrow-derived mesenchymal stem cells. Stem Cell Res Ther 2017;8:102

20. Armiñán A, Gandía $C$, Bartual $M$, García-Verdugo JM, Lledó E, Mirabet V, Llop M, Barea J, Montero JA, Sepúlveda P. Cardiac differentiation is driven by NKX2.5 and GATA4 nuclear translocation in tissue-specific mesenchymal stem cells. Stem Cells Dev 2009;18:907-918

21. Yi Q, Xu H, Yang K, Wang Y, Tan B, Tian J, Zhu J. Islet-1 induces the differentiation of mesenchymal stem cells into cardiomyocyte-like cells through the regulation of Gcn5 and DNMT-1. Mol Med Rep 2017;15:2511-2520

22. Genead R, Danielsson C, Andersson AB, Corbascio M, Franco-Cereceda A, Sylvén C, Grinnemo KH. Islet-1 cells are cardiac progenitors present during the entire lifespan: from the embryonic stage to adulthood. Stem Cells Dev 2010;19:1601-1615 